ARTICLE INFO

Submitted: 14-04-2016 Accepted: 27-04-2016

\section{Urgent Need to Train Teachers and Students in First Aid and CPR}

\author{
Z. Zayapragassarazan
}

Department of Medical Education, Fawaharlal Institute of Postgraduate Medical Education and Research (FIPMER), India

To cite this article: Z. Zayapragassarazan. Urgent need to train teachers and students in first aid and CPR. Education in Medicine Journal. 2016;8(2):89-92. DOI: 10.5959/eimj.v8i2.435

To link to this article: http://dx.doi.org/10.5959/eimj.v8i2.435

\begin{abstract}
This article is my reflection about the recent incident that took place in a sports ground in Pondicherry, India where a 17-year-old school boy collapsed and died in the sports ground after running only 80 meters in the 1500 meters race. The cause of death was an underlying cardiac cause that has manifested during the athletic event. The stress caused by intense, excessive exercise can negatively affect the cardiovascular system. If the boy had received the first line of treatment with the cardiopulmonary resuscitation (CPR) on the spot, he may have survived. This incident made me to develop some insights on how to prevent such tragedies by throwing light on the need to prepare our students and teachers who are organisers of such events by providing them training and certification in first aid and CPR so that they can effectively participate as rescuers when faced with such emergency situation to save the life of the concerned. This article also stresses the need for policy measures from the government side to include first aid and CPR as a mandatory subject at all levels of education to teach the next generation of life savers.
\end{abstract}

Keywords: Athlete death, CPR, First aid, Schools, Teachers, Students

CORRESPONDING AUTHOR Dr. Z. Zayapragassarazan, Associate Professor of Educational Technology, Department of Medical Education, JIPMER Academic Centre, Jawaharlal Institute of Postgraduate Medical Education and Research (JIPMER), Puducherry-605006, India. | Email: zprazan@yahoo.co.in

Reflection offers an opportunity to consider how our personal experiences and observations shape our thinking and acceptance of new ideas. This reflective article is about my insights developed after hearing the sudden death of a school boy in a sports ground during an athlete meet. The incident happened on 21 February 2016 during the Inter-school athletic meet at Pondicherry. An eleventh standard boy aged about 17 years ran for about 80 meters only in the 1500 meters race and he fell down on the track and became motionless at around $9.00 \mathrm{am}$. He was lifted and taken to General Hospital which is just a kilometre away from the venue. The doctors declared him as "brought dead". The boy was a keen football player and used to take part in regular practice and school level tournaments. It is believed that the cause of death was an underlying cardiac cause that has manifested during the athletic event (1).

Sudden cardiac death (SCD) is a dramatic and/or spontaneous death that is usually caused by a heart condition $(2,3)$. Another thing that can be considered as an underlying cause is Sudden Arrhythmic Death Syndrome (SADS). In about 1 in every 20 cases of SCD, no definite cause 
of death can be found, even after the heart has been examined by an expert cardiac pathologist. This is then called SADS. In the past it has also been called Sudden Adult Death Syndrome or Sudden Death Syndrome but, because it affects children too, the term SADS is now used $(4,5)$.

Exercise is one of the greatest stresses the cardio vascular system can face (3). According to reliable sources the boy never had any health problem. This gives an indication that just because someone is an athlete does not mean that he or she is healthy or not having any cardiac illness whatsoever. The first line of treatment for any sudden collapse is to check for vitals and proceed with the cardiopulmonary resuscitation (CPR) and then to advance cardiac support with the help of a medical doctor in a hospital set up (6).

This is not only a tragedy for the person and his family, but a great loss for society too. We may still be asking why it happened, and how it could have happened to someone so young and who perhaps seemed so healthy. Having heard and read about this incident that took place in my city, I could not just feel grieved for the incident that took place but also wanted to create awareness about the same so that in future such loss can be avoided. I also believe my reflections about this incident would serve as educational intervention to the people concerned to take part in creating awareness about this silent disease. The other issue that props up in my mind is that, if someone would have done a $\mathrm{CPR}$ on the boy he may have survived.

Here the questions are:

1. What may be the possible cause of this sudden and unexplained death?

2. What should the organisers (who are mostly teachers and physical education teachers) do when face with such a situation?

3. How can the organisers be trained to successfully face such emergency lifesaving situation?
4. Are teachers required to be certified in CPR and first aid training?

5. Can compulsory in-service training to encounter common emergency incidents among school children help them to become life savers?

In this context, I would like to throw light on the following:

The team members of the organising committee should be more self-sufficient to respond quickly and correctly to such a disaster, and this requires teamwork and training. The success of the response may depend on the team's knowledge and skills. Properly trained members can make the difference between life and death by treating medical emergencies quickly. For this team members should learn basic first aid and cardio- pulmonary resuscitation (CPR), as well as how to recognise medical emergencies and assess medical conditions (6).

First Aid and CPR training is becoming more common in non-medical settings, including the community, workplace, and schools which was once often associated with medical personnel and health care professionals. Now it is the need of the hour to examine the importance of including first aid and CPR knowledge and skills in the teacher education curriculum and even in the school curriculum from the perspective of teachers including physical education teachers and students. Early initiation of excellent CPR and early defibrillation are associated with significantly improved survival rates (6).

Educational institutions conducting athletic or sports events must have a structured emergency action plan developed with the help of emergency medical services department of government hospitals. The emergency plan should be specific to the sports venue.

The persons who are identified as first or immediate responders should be a trained and certified person in first aid and CPR. 
The sports venue should have emergency equipment, communication devices, assistants, and transportation facilities.

The coach or the trainers of sports or athletics are very often the first responders caring for our sports persons or athletes and they are not prepared to meet such emergencies or even if they are aware of first aid or CPR they don't come forward to help the victim because of lack of confidence.

The real people that we need to train to recognise cardiac arrest are the coaches, teammates, the officials to recognise cardiac arrest and initiate necessary life saving measures following a standard emergency action plan. Such trainings can also be provided to students so that they can act as lifesaving agents in public places. Also there must be a clear periodic health check for athletes and sports people for any underlying medical illness.

The concerned authorities trained in emergency action plan should certify the safety of playground for conducting such sports events. There should be school wise or state wise students' health policy in place.

Only teachers and physical education teachers certified with first aid and or CPR can organise such sports events. Such sports events should be organised with the assistance and presence of a medical team in the venue. Physical education teachers should be confident enough in dealing with medical emergencies like sudden collapse, potential fractures, breaks and sprains and spinal injuries. They should also be skilled enough to check the vitals of the injured and take necessary steps to inform the concerned to proceed further for medical treatment. For this, first aid and CPR training should be made compulsory as part of teacher training and physical education training. Frequent practice drill or mock drills should be in place to check the readiness of the teachers to effectively participate when faced with such emergency situation.
The urgent need today is that every man, woman, and child should know what to doif faced with an accident or sudden injury to save life, protect a person from further injury, prevent an injury or illness becoming worse and to obtain expert help. To achieve this goal first aid is the immediate and essential requirement (7).

It is suggested that all adults should be able to administer first aid since everyone is expected to experience emergency situations at any time. The level of knowledge of first aid is essential for all levels of students and teachers. The need for introducing formal first aid training classes for teachers and students has become imperative so that the trained teachers and students become competitive enough to provide first aid independently and spontaneously in real life situations $(8,9)$.

First aid education of school teachers is too important and too indispensable to be provided by teacher training courses. It should be kept in mind that a child's life can be saved or disabilities which might last for a life time can be prevented with a qualified education given to this group (10).

This is a great opportunity for the Government of India to have a dialog with schools about the whole issue and include first aid and CPR as a mandatory subject at all levels of education to teach the next generation of life savers. This will add thousands of trained rescuers to the population every year.

\section{References}

1. Sivaraman R. Athlete collapses on track, dies in hospital. The Hindu. 2016 February 22.

2. Davies MJ. Unexplained death in fit young people. BMJ. 1992;305(6853):538-539. doi: 10.1136/bmj.305.6853.538.

3. Maron BJ. Distinguishing hypertrophic cardiomyopathy from athlete's heart physiological remodelling: clinical significance, diagnostic strategies and 
implications for preparticipation screening. Br J Sports Med. 2009;43:649-656. doi:10.1136/bjsm.2008.054726.

4. Corrado D, Basso C, Thiene G. Sudden cardiac death in young people with apparently normal heart. Cardiovasc Res. 2001;50(2):399-408. doi:10.1016/S00086363(01)00254-1.

5. Koplan BA, Stevenson WG. Sudden arrhythmic death syndrome. Heart. 2007;93(5):547-548. doi: 10.1136/ hrt.2006.108134.

6. Pozner CN. Supportive data for advanced cardiac life support in adults with sudden cardiac arrest. [updated 2016 May 31; Accessed on 2016 June 27]. Available from: http://www.uptodate.com/contents/ advanced-cardiac-life-support-acls-in-adults
7. Miles S. First-aid training. BMJ. 1969;4(5681):485-487. doi: 10.1136/ bmj.4.5681.485.

8. Khatatbeh M. First aid knowledge among university students in Jordan. Int $\mathrm{J}$ Prev Med. 2016;7: 24 . doi: 10.4103/20087802.174772 .

9. Joseph N, Kumar GS, Babu YPR, Nelliyanil M, Bhaskaran U. Knowledge of first aid skills among students of a medical college in Mangalore City of South India. Ann Med Health Sci Res. 2014;4(2):162-166. doi: 10.4103/2141-9248.129022.

10. Sonmez Y, Uskun E, Pehlivan A. Knowledge levels of pre-school teachers related with basic first-aid practices, Isparta sample. Turk Pediatri Ars. 2014;49(3):238-246. doi: 10.5152/tpa.2014.1581. 